\title{
Simulation of Soil Water and Heat Flow under Plastic Mulching and Different Ridge Patterns
}

\author{
Ruofan Li, Juanjuan Ma *, Xihuan Sun, Xianghong Guo and Lijian Zheng
}

check for updates

Citation: Li, R.; Ma, J.; Sun, X.; Guo, X.; Zheng, L. Simulation of Soil Water and Heat Flow under Plastic Mulching and Different Ridge Patterns. Agriculture 2021, 11, 1099. https:// doi.org/10.3390/agriculture11111099

Academic Editors: Peiling Yang, Renkuan Liao and Yunkai Li

Received: 17 September 2021

Accepted: 29 October 2021

Published: 4 November 2021

Publisher's Note: MDPI stays neutral with regard to jurisdictional claims in published maps and institutional affiliations.

Copyright: (c) 2021 by the authors. Licensee MDPI, Basel, Switzerland. This article is an open access article distributed under the terms and conditions of the Creative Commons Attribution (CC BY) license (https:// creativecommons.org/licenses/by/ $4.0 /)$.
College of Water Resource Science and Engineering, Taiyuan University of Technology, Taiyuan 030024, China; liruofan0063@link.tyut.edu.cn (R.L.); sunxihuan@tyut.edu.cn (X.S.); gxhtylg@163.com (X.G.); zhenglijian@tyut.edu.cn (L.Z.)

* Correspondence: mjjsxty@126.com

Abstract: The ridge-furrow mulching system with plastic film (RFMS) has been widely used in semiarid areas in order to improve soil water and heat conditions, crop yields and water use efficiency. It is of practical significance to study the effect of mulching and ridge types on soil water and heat in order to optimize mulching measures and improve the effectiveness of the ridge and furrow system. To clarify the combined effect of soil water and heat beneath the system and the influence of ridge morphology on it, field experiments were conducted with three treatments, including conventional planting in bare land (CK), a ridge-furrow (wide ridge with $70 \mathrm{~cm}$ width and $10 \mathrm{~cm}$ height, narrow ridge with $40 \mathrm{~cm}$ width and $15 \mathrm{~cm}$ height) mulching system with complete plastic film (RFWN) and a ridge-furrow (equal ridge with $55 \mathrm{~cm}$ width and $15 \mathrm{~cm}$ height) mulching system with complete plastic film (RFE). An insufficient irrigation system was adopted and the two-dimensional numerical software HYDRUS-2D was used to simulate the soil water and heat flow under the experimental conditions. The model was calibrated and verified according to test data for the period of 2018 to 2019, which showed good agreement between the simulated and measured values. The simulation results revealed that the ground temperatures of RFWN and RFE were much higher than that of CK, and the average value of $0-25 \mathrm{~cm}$ during the growth period could increase by $2.29-4.61 \%$. Compared with CK, RFWN and RFE reduced soil evaporation (84.71-93.73\%) and field evapotranspiration (12.02-21.75\%), while they increased root water uptake (25.87-40.98\%) and T/ET (48.85-80.15\%). Plastic film mulching and ridge morphologies affected the infiltration range and the direction of soil water movement, increased soil moisture when there was no rainfall or irrigation and reduced soil water and heat fluctuations, which was more conducive to crop growth, especially under the RFWN system. The simulation method proposed in this paper is an effective technique for calculating the soil water and heat dynamics under different ridge and furrow sections under the condition of film mulching, and it can be used for the optimal management of soil water and heat in this area.

Keywords: full plastic film mulching; ridge morphologies; soil water and heat; HYDRUS-2D; water balance

\section{Introduction}

As a physical barrier to the exchange of water vapor between the soil and the atmosphere, film mulching could limit soil evaporation [1], control soil water and heat, change the soil micro-ecological environment [2], significantly promote crop emergence and dry matter accumulation and ultimately improve soil water use efficiency [3]; thus, it has been widely used in most arid and semi-arid arable lands throughout the world [4]. Plastic film mulching is usually coordinated with other measures [5]. Its combination with a ridge and furrow system (MRFS) has been shown to be beneficial to increase crop yields and water use efficiency [6-9] and has been verified in the planting of corn [10], wheat [11], potato [12] and other crops [13]; using this in combination with insufficient irrigation has been confirmed to achieve the dual purpose of saving water and increasing production $[14,15]$, and a moderate water deficit under mulching can result in higher water content, higher yields 
and reduced irrigation water [15]. Under the condition of full-film double-ridge planting, the planting holes in the furrow are used for the aeration and infiltration of rainfall or irrigation [16]; the soil micro-topography and mulching result in uneven distributions of water and heat, which affect crop physiology activity and in turn impact soil water and heat transfer [17]. To date, the dynamics and distribution of soil water and heat flow under full-film double ridges with inadequate irrigation have not been fully studied. Therefore, quantitative research on soil water and heat status has important practical significance as it could contribute to revealing the internal water-saving and yield-increasing mechanisms of the planting system and provide a theoretical basis for the optimization of cover measures.

The ridge-furrow patterns affect soil moisture, soil temperature, crop yield and water use efficiency [18], and a ridge-furrow system with an appropriate morphology can improve soil water and heat conditions and increase crop yields more effectively [19]. Studies have shown that increasing the ridge width has a positive effect on soil water and heat conditions, which increases leaf photosynthesis, dry matter accumulation on the ground, crop yield and water use efficiency [6]. However, crop yield will not increase indefinitely with an increase in ridge width [20] under the same planting density, and a reasonable ridge-furrow structure is essential for crop cultivation in semi-arid areas. Previous studies on soil water-heat coupling dynamics mainly focused on different mulching methods (such as mulching on ridges, full mulching, double-ridge mulching, etc.) [21] or the mulching period [22], but the influence of the ridge-furrow morphology on soil water and heat under RFMS remains unclear. Research on the combined effects of soil water and heat flow in different ridge-furrow patterns can provide a theoretical basis for optimizing the ridge and furrow system, which would be conducive to improving the soil water and heat environment, increasing crop yields and the effectiveness of the system.

The soil hydrothermal status has complex effects on crop emergence [23], root and crown status [24], dry matter accumulation [25], yield and resource utilization efficiency [26], etc. Research on soil hydrothermal status is of great significance to crop growth. However, it is difficult to calculate the water and heat flow in the full-film double-ridge planting system, as the dynamic migration of water and heat is closely related and complicated under this condition. Moreover, there also exist challenges in analyzing the water and heat transfer process at different locations in a long series and quantitatively through field test monitoring; thus, numerical simulation methods are required [11]. Among the available models (including SVAT, SHAW and HYDRUS) that can simulate the transport of water, heat and solute in variable-saturated porous media, we use the HYDRUS model in this work [27]. The geometric dimensions of ridges and furrows can be considered explicitly in HYDRUS-2D, whose effectiveness and accuracy for two-dimensional soil water and heat transport simulation have been verified by many scholars [28-31]. Most previous studies considered a no-flux boundary under film mulched areas [30,31], but the variable-flux boundary has been confirmed to be more practical [32] and was therefore adopted in this paper.

To date, the simulations of soil water and heat transfer under the condition of full-film double-ridge planting with film hole irrigation has not been reported, and the influence of ridge patterns on the distribution of soil water and heat is still unclear. This article will focus on the above issues, and the main purposes are to:

(1) Calibrate and verify the effectiveness of HYDRUS-2D modeling under the conditions of full-film double-ridge planting;

(2) Simulate the temporal and spatial distribution of soil water-heat flow and laws of water balance under different planting conditions;

(3) Explore the influence of plastic film mulching and different ridge morphologies on the distribution of soil water and heat flow and provide a theoretical basis for the design of ridge and furrow coverage systems. 


\section{Materials and Methods}

\subsection{Experimental Site Description}

The experiment was conducted at Dongyang Experimental Demonstration Base (N37 $\left.32^{\prime} 44.28^{\prime \prime}, \mathrm{E} 112^{\circ} 37^{\prime} 26.78^{\prime \prime}\right)$, Yuci District, Jinzhong City, Shanxi Province, from May to August in 2018 and 2019. In 2018, plants were sowed on 27 May and harvested on August 8 in the film mulching area and 12 August on bare land; in 2019, plants were sowed on 19 May and harvested on August 8 in the film mulching area and August 13 on bare land. The base experiences the typical temperate continental monsoon climate. The mean annual air temperature is approximately $9.3^{\circ} \mathrm{C}$, the mean annual precipitation amounts to $430 \mathrm{~mm}$, the frost-free period lasts 154 days, the soil type is tidal soil, the surface soil texture is medium loam, the $\mathrm{pH}$ is 8.55 , the soil total nitrogen is $0.78 \mathrm{~g} \cdot \mathrm{kg}^{-1}$, the organic matter is $10.35 \mathrm{~g} \cdot \mathrm{kg}^{-1}$, the alkali hydrolyzed nitrogen is $52 \mathrm{mg} \cdot \mathrm{kg}^{-1}$, the available phosphorus is $49.12 \mathrm{mg} \cdot \mathrm{kg}^{-1}$, the available potassium is $251.29 \mathrm{mg} \cdot \mathrm{kg}^{-1}$, field water capacity is $32.8 \%$ (volumetric water content), wilting coefficient is $11 \%$ (volumetric water content) and soil bulk density is $1.37 \mathrm{~g} \cdot \mathrm{cm}^{-3}$ at effective root depth $(0-100 \mathrm{~cm}$, the main soil layer at which crop roots absorb water and nutrients). Foundation soil samples and moisture constants are shown in Table 1.

Table 1. Foundation soil samples and moisture constants.

\begin{tabular}{ccccc}
\hline $\begin{array}{c}\text { Soil Layer } \\
\mathbf{~ c m}\end{array}$ & Texture & $\begin{array}{c}\text { Bulk Density } \\
\mathbf{g} \cdot \mathbf{c m}^{-\mathbf{3}}\end{array}$ & $\begin{array}{c}\text { Field Capacity } \\
\mathbf{V} \%\end{array}$ & $\begin{array}{c}\text { Wilting } \\
\text { Coefficient V\% }\end{array}$ \\
\hline $0-20$ & silt loam & 1.22 & 32.7 & 11.6 \\
$20-40$ & silt loam & 1.47 & 30.9 & 14.0 \\
$40-60$ & silt loam & 1.39 & 31.6 & 11.9 \\
$60-80$ & loam & 1.37 & 32.9 & 7.1 \\
$80-100$ & silt loam & 1.42 & 35.9 & 10.3 \\
\hline
\end{tabular}

The precipitation amounts and daily temperatures during the two-year experimental growth period are shown in Figure 1.
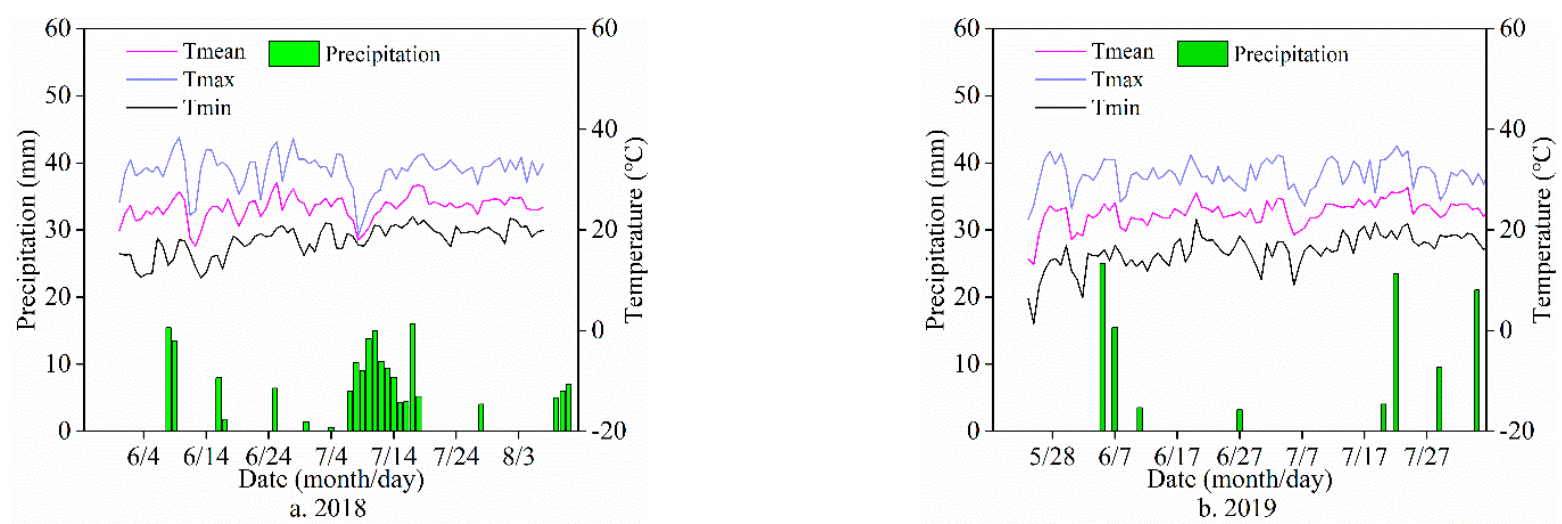

Figure 1. Daily maximum and minimum temperatures, average temperatures and precipitation in experimental site throughout the waxy maize growing seasons. (a) The data in 2018; (b) The data in 2019.

\subsection{Experimental Design}

A plot experiment in the field was conducted, and 3 planting methods were included: conventional planting in bare land (CK), a ridge-furrow (wide ridge with $70 \mathrm{~cm}$ width and $10 \mathrm{~cm}$ height, narrow ridge with $40 \mathrm{~cm}$ width and $15 \mathrm{~cm}$ height) mulching system with complete plastic film (RFWN) and a ridge-furrow (equal ridge with $55 \mathrm{~cm}$ width and $15 \mathrm{~cm}$ height) mulching system with complete plastic film (RFE) (for comparing the influence of ridge patterns on soil water and heat flow). The plant spacing was $30 \mathrm{~cm}$, and an insufficient irrigation system was used to control the soil water content at the appropriate 
level during the 4 periods (the sowing period, the seedling period to the pre-joining period, the late jointing period to the booting period and the booting period to the flowering period were, respectively, $75-85 \%, 65-75 \%, 70-80 \%$ and $70-80 \%$ of the field water capacity), the pre- and late joining periods were divided by 7 expanded leaves as nodes, and the planned wet layer was $40 \mathrm{~cm}$ in seedling stage and $60 \mathrm{~cm}$ from jointing stage to maturity stage. Irrigation methods were furrow irrigation in CK and film hole irrigation in RFWN and RFE. The soil moisture was monitored weekly, and it was irrigated to the upper limit if the water content was below the lower limit. There were 3 treatments in the experiment, with a random block design; the plot contained 6 rows with $6 \mathrm{~m}$ length, and each treatment was repeated 4 times. No cultivation was carried out during the experiment's execution, and the amount of fertilizer applied was determined according to the basic fertility of the soil and the local experience level. The application amount of nitrogen fertilizer was $180 \mathrm{~kg} \cdot \mathrm{hm}^{-2}$ (based on pure N), the ratio of N, P and K was approximately 3:1:2, and the application of each treatment was the same and conducted as base fertilizer before sowing. The field layout is shown in Figure 2.

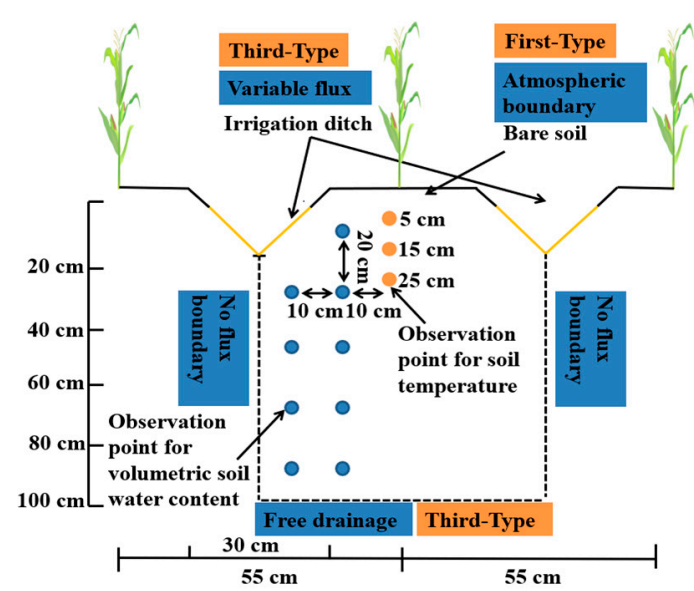

(a)

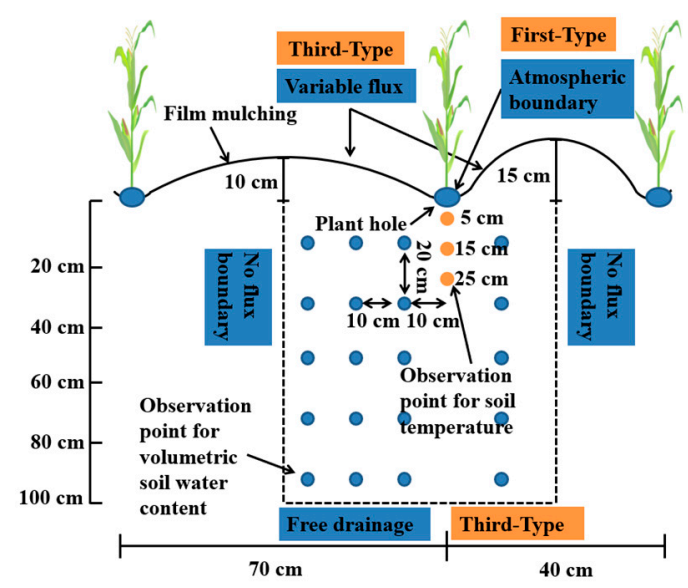

(b)

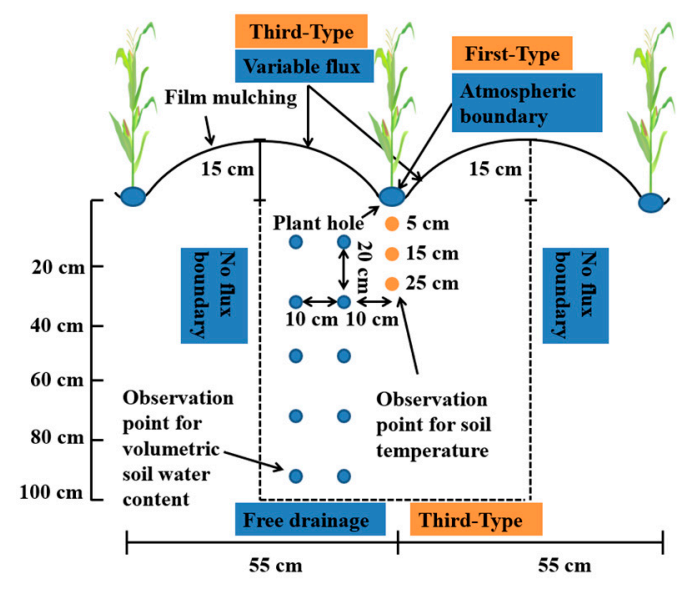

(c)

Figure 2. Experimental layout and observation nodes, boundary conditions for soil water and heat flow under different treatments in HYDRUS-2D modeling. (a) Treatment CK; (b) Treatment RFWN; (c) Treatment RFE.

\subsection{Measurements}

The Adcon-Ws wireless automatic weather monitoring system was used to determine the temperature, rainfall, relative humidity, wind speed and direction and solar radiation at a height of $2 \mathrm{~m}$ in the test field, and data collection was performed every $15 \mathrm{~min}$. The 
HZR-8T soil layer temperature tester was buried in each plot at $0,5,15$ and $25 \mathrm{~cm}$ as in Figure 2, measured every $2 \mathrm{~h}$ throughout the entire growth period. The soil moisture was measured using the drying method at the location in Figure 2, and every $20 \mathrm{~cm}$ was a layer in the range of $0-100 \mathrm{~cm}$. Five maize plants with uniform growth were selected and marked from each plot, their leaf areas were measured with a steel ruler at each growth period, and $L A I$ was calculated by the length-width coefficient method and fitted with a logistic equation to calculate daily ETc.

\subsection{Construction of Mathematical Model of Water and Heat Transport}

HYDRUS-2D was used to simulate water and heat transfer under different treatments. The model uses the Galerkin finite element to solve the Richards equation of water flow in variable saturation porous media and the convection dispersion equation of heat transport.

\subsubsection{Soil Water Flow}

Soil water movement in the test plot was simulated as water movement on a twodimensional vertical plane, neglecting vapor flow; the governing equation of water flow with root uptake functions is expressed as follows [33]:

$$
\frac{\partial \theta(h)}{\partial t}=\frac{\partial}{\partial x}\left[K(h) \frac{\partial h}{\partial x}\right]+\frac{\partial}{\partial z}\left[K(h) \frac{\partial h}{\partial z}+K(h)\right]-S(h)
$$

where $\theta$ is the volumetric moisture content $\left(\mathrm{cm}^{3} \cdot \mathrm{cm}^{-3}\right) ; h$ is the pressure head $(\mathrm{cm}) ; K(h)$ is the unsaturated hydraulic conductivity of the liquid phase $\left(\mathrm{cm} \cdot \mathrm{d}^{-1}\right) ; t$ is time $(\mathrm{d}) ; x$ and $z$ are horizontal and vertical coordinates $(\mathrm{cm}) ; S$ is a sink term referring to root water uptake $\left(\mathrm{d}^{-1}\right)$.

The van Genuchten-Mualem model [34] was used as the soil hydraulic function, expressed by:

$$
\begin{gathered}
\theta(h)=\theta_{r}+\frac{\theta_{s}-\theta_{r}}{\left[1+|\alpha h|^{n}\right]^{m}} m=1-\frac{1}{n}, n>1 \\
K(h)=K_{s} S_{e}^{l}\left[1-\left(1-S_{e}^{1 / m}\right)^{m}\right]^{2} \\
S_{e}=\frac{\theta(h)-\theta_{r}}{\theta_{s}-\theta_{r}}
\end{gathered}
$$

where $\theta s$ is the soil moisture content at saturation $\left(\mathrm{cm}^{3} \cdot \mathrm{cm}^{-3}\right) ; \theta r$ is the residual soil moisture content $\left(\mathrm{cm}^{3} \cdot \mathrm{cm}^{-3}\right) ; n, m, \alpha$ are empirical shape parameters; $S e$ is effective saturation; $K s$ is the saturated hydraulic conductivity $\left(\mathrm{cm} \cdot \mathrm{d}^{-1}\right) ; l$ is the pore connectivity parameter, which normally is set to 0.5 [35].

\subsubsection{Root Water Uptake}

The sink term $S(h)$ in Equation (1), which represents root water absorption, was calculated according to the Feddes model [36]:

$$
\begin{gathered}
S(h, x, z)=\alpha(h) b(x, z) T_{p} L_{t} \\
b(x, z)=\frac{b^{\prime}(x, z)}{\int_{\Omega_{R}} b^{\prime}(x, z) \mathrm{d} \Omega} \\
\alpha(h)=\left\{\begin{array}{c}
\frac{h_{1}-h}{h_{1}-h_{2}} h_{2}<h \leq h_{1} \\
1 h_{3} \leq h \leq h_{2} \\
\frac{h-h_{4}}{h_{3}-h_{4}} h_{4} \leq h<h_{3}
\end{array}\right.
\end{gathered}
$$

where $b(x, z)$ is the water uptake distribution function $\left(\mathrm{cm}^{-2}\right)$; Tp is the potential transpiration $\left(\mathrm{cm} \cdot \mathrm{d}^{-1}\right) ; \alpha(h)$ is the water stress response function due to root water uptake, which is dimensionless; $L t$ is the surface length associated with transpiration $(\mathrm{cm}) ; h_{1}$ is the pressure 
head at the anaerobic point of root water absorption $(\mathrm{cm}) ; h_{2}$ is the optimum pressure head for root water absorption $(\mathrm{cm}) ; h_{3}$ is the pressure head at the end of root water absorption $(\mathrm{cm}) ; h_{4}$ is the pressure head at the point where root water absorption is weak $(\mathrm{cm})$. The root water uptake parameters refer to the reference values proposed by Wesseling et al. [37] and were directly selected in the software. By integrating Equation (5) in the root zone, the total actual root water uptake could be obtained. In HYDRUS-2D, $b(x, z)$ was calculated according to the model proposed by Vrugt et al. [38]:

$$
b(x, z)=\left[\left(1-\frac{z}{Z_{m}}\right)\right]\left[\left(1-\frac{x}{X_{m}}\right)\right] e^{-\left(\frac{p_{z}}{z m}\left|z^{*}-z\right|+\frac{p_{x}}{X_{m}}\left|x^{*}-x\right|\right)}
$$

where $Z_{m}$ and $X_{m}$ are the maximum depth and horizontal distance of the root distribution, respectively; $z^{*}$ and $x^{*}$ are the vertical and horizontal coordinates of maximum root density, respectively; $p_{z}$ and $p_{x}$ are empirical parameters of root asymmetry.

\subsubsection{Soil Heat Flow}

The soil two-dimensional heat transport function, neglecting water vapor transport, was calculated according to [39]:

$$
C(\theta) \frac{\partial T}{\partial t}=\frac{\partial}{\partial x_{i}}\left[\lambda_{i j}(\theta) \frac{\partial T}{\partial x_{j}}\right]-C_{w} q_{i} \frac{\partial T}{\partial x_{i}}
$$

where $C(\theta)$ is the total volumetric heat capacity of porous media $\left(\mathrm{J} \cdot \mathrm{cm}^{-3} \cdot{ }^{\circ} \mathrm{C}^{-1}\right) ; T$ is the soil temperature $\left({ }^{\circ} \mathrm{C}\right) ; \lambda_{i j}(\theta)$ is the soil thermal conductivity $\left(\mathrm{W} \cdot \mathrm{cm}^{-1} \cdot{ }^{\circ} \mathrm{C}^{-1}\right) ; C_{w}$ is the volumetric heat capacity of liquid $\left(\mathrm{J} \cdot \mathrm{cm}^{-3} \cdot{ }^{\circ} \mathrm{C}^{-1}\right) ; q_{i}$ is water flux $\left(\mathrm{cm} \cdot \mathrm{d}^{-1}\right) . C(\theta)$ is calculated by the following formula [40]:

$$
C(\theta)=C_{n} \theta_{n}+C_{o} \theta_{o}+C_{w} \theta
$$

where the subscripts $\mathrm{n}, \mathrm{o}$ and $\mathrm{w}$ represent the solid phase, organic matter and liquid phase in the soil, respectively. $\lambda_{i j}(\theta)$ is calculated as follows [41]:

$$
\lambda_{i j}(\theta)=\lambda_{T} C_{w}|q| \delta_{i j}+\left(\lambda_{L}-\lambda_{T}\right) C_{w} \frac{q_{j} q_{i}}{|q|}+\lambda_{0}(\theta) \delta_{i j}
$$

where $\lambda_{T}$ is the transverse thermal dispersion $(\mathrm{cm}) ; \lambda_{L}$ is the longitudinal thermal dispersion $(\mathrm{cm}) ; \delta_{i j}$ is the Kronecker delta function; $\lambda_{0}(\theta)$ is the thermal conductivity, which is calculated by the following formula [42]:

$$
\lambda_{0}(\theta)=b_{1}+b_{2}+b_{3} \theta^{0.5}
$$

where $b_{1}, b_{2}, b_{3}$ are empirical coefficients $\left(\mathrm{W} \cdot \mathrm{m}^{-1} \cdot{ }^{\circ} \mathrm{C}^{-1}\right)$.

\subsubsection{Definite Solution Condition}

In this study, the simulation area is a two-dimensional area centered on waxy corn plants and has a horizontal extension of 0.5 times each row spacing, which coincides with the midpoint of the row spacing on both sides, and the vertical extension is $1.0 \mathrm{~m}$. The finite element grid size is $0.5 \mathrm{~cm}$ for $0-20 \mathrm{~cm}, 1 \mathrm{~cm}$ for $20-60 \mathrm{~cm}$ and $3 \mathrm{~cm}$ for $60-100 \mathrm{~cm}$. The software cannot identify whether the film is covered or not; thus, it is distinguished by the setting of boundary conditions, as shown in Figure 2. The water and heat boundaries were set, respectively, as the no-flux boundary on the vertical side, free drainage and the third type on the bottom boundary, the atmosphere boundary and the first type on the plant hole, variable flux and the third type on the mulching area under RFWN and RFE, variable flux and the third type on the wetted area of irrigation furrow, and the atmosphere boundary and the first type on the remaining section under CK at the surface. 
Assuming that the initial soil water content and soil temperature were evenly distributed in the horizontal direction, the initial conditions for soil moisture and temperature movement were:

$$
\begin{aligned}
& \theta_{i}(x, z, 0)=\theta_{0 i} 0 \leq x \leq 55 \mathrm{~cm} ; 0 \leq z \leq 100 \mathrm{~cm} ; i=1, \cdots, 5 \\
& T_{i}(x, z, 0)=T_{0 i} 0 \leq x \leq 55 \mathrm{~cm} ; 0 \leq z \leq 100 \mathrm{~cm} ; i=1, \cdots, 5
\end{aligned}
$$

The software requires potential transpiration $(T p)$ and potential evaporation $(E p)$ as input items. Zhang et al. [30] neglected the soil evaporation under the full-film condition, and the product of the substance coefficient $K c b$ and $E T_{0}$ was used as the Tp input model. Zhao et al. [31] calculated Ep and Tp according to Beer's law and revised them by the parameters $f m$ (characterizing the covering material) and $c_{m}$ (characterizing the coverage ratio), respectively. In this study, we considered the film pore evaporation under the condition of full-film mulching, using the dual crop coefficient method of FAO-56 [43] and the field water balance to calculate the daily $T p$ and $E p$, in which the parameters were obtained using a genetic algorithm. The input precipitation in the furrow was increased by a factor of 2 in order to reflect the rain collection effect of the full-film double ridge under RFWN and RFE conditions.

\subsubsection{Parameter Calibration}

The parameters were optimized using the actual measured values of soil moisture and temperature during the growth period of waxy corn in 2019. The soil particle data were obtained from the HWSD soil database, from which the percentages of clay, sand and silt in the $0-30 \mathrm{~cm}$ and $30-100 \mathrm{~cm}$ soil layers could be obtained. Therefore, the soil texture of the simulation area was divided into two layers, and the soil hydraulic parameters were predicted by the software based on the soil bulk density combined with the soil texture data. The software parameter optimization was performed by inverse calculation, which is based on the Levenberg-Marquardt nonlinear minimization method. The estimated parameters were used as the initial values of inverse calculation to optimize $\theta_{r}, \theta_{s}, \alpha, n$ and $K_{s}$, so that the simulated values and the observed values of soil moisture could achieve better fitting. Hydrothermal coupling simulations for each treatment were conducted to optimize the soil heat flow parameters of $0-30 \mathrm{~cm}$ after determining the soil water flow parameters, and the initial values of the heat flow parameters were the software default values. The optimized soil water and heat parameters are shown in Tables 2 and 3.

\begin{tabular}{|c|c|c|c|c|c|c|c|}
\hline & & $\begin{array}{c}Q r \\
\left(\mathrm{~cm}^{3} \cdot \mathrm{cm}^{-3}\right)\end{array}$ & $\begin{array}{c}Q s \\
\left(\mathrm{~cm}^{3} \cdot \mathrm{cm}^{-3}\right)\end{array}$ & $\alpha\left(1 \cdot \mathrm{cm}^{-1}\right)$ & $n$ & $K s\left(\mathrm{~cm} \cdot \mathrm{d}^{-1}\right)$ & $l$ \\
\hline \multirow{2}{*}{ Bare soil } & $0-30 \mathrm{~cm}$ & 0.0806 & 0.4828 & 0.0216 & 1.503 & 192.1 & 0.5 \\
\hline & $30-100 \mathrm{~cm}$ & 0.0722 & 0.398 & 0.0116 & 1.472 & 81.61 & 0.5 \\
\hline \multirow{2}{*}{ Mulched } & $0-30 \mathrm{~cm}$ & 0.0497 & 0.4325 & 0.0324 & 1.581 & 106.7 & 0.5 \\
\hline & $30-100 \mathrm{~cm}$ & 0.0549 & 0.4231 & 0.0255 & 1.487 & 61.32 & 0.5 \\
\hline
\end{tabular}

Table 2. Model parameters to simulate soil water flow.

Table 3. Model parameters to simulate soil heat flow.

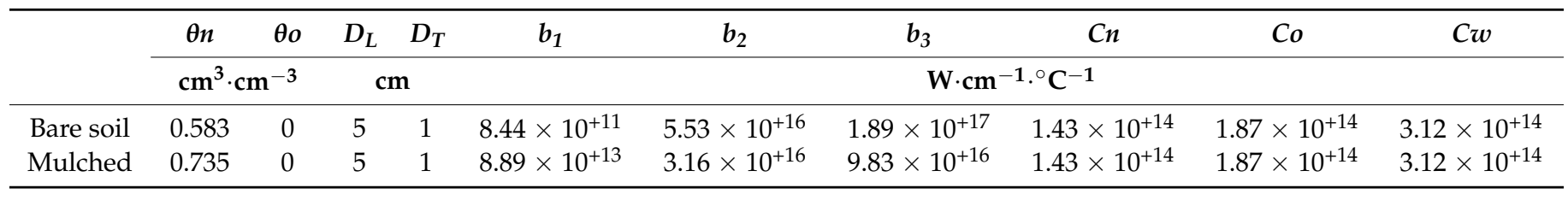


$R^{2}$ was used to reflect the correlation between simulated and observed soil moisture and temperature, and RMSE and MRE were used to evaluate the performance of the model. The calculation formulas are as follows:

$$
\begin{gathered}
R M S E=\sqrt{\sum_{1}^{N} \frac{\left(S_{i}-O_{i}\right)^{2}}{N}} \\
M R E=\frac{1}{N} \sum_{1}^{N} \frac{\left|S_{i}-O_{i}\right|}{S_{i}} \times 100 \%
\end{gathered}
$$

where $O_{i}$ is the observed value, $S_{i}$ is the simulated value, $\bar{O}$ is the average observed values, and $N$ is the total number of observed values.

\section{Results}

\subsection{Model Calibration and Validation}

The measured soil temperature and water content in 2019 were used to calibrate the model parameters, and the experimental data in 2018 were used to verify the model. The parameters obtained by calibration (shown in Tables 2 and 3) were used to simulate the soil moisture and temperature of observation points in each treatment in 2019 (the locations of observation points are shown in Figure 2). The observed and simulated values at different soil layers and different times in each treatment are shown in Figure 3. It can be seen from the figure that the simulated and observed values of different treatments were essentially evenly distributed on both sides of the 1:1 line. The ranges of RMSE, MRE and $R^{2}$ values for soil moisture and temperature were $0.015-0.017 \mathrm{~cm}^{3} \cdot \mathrm{cm}^{-3}, 5.36-7.03 \%$ and $0.61-0.77$ and $0.65-0.81{ }^{\circ} \mathrm{C}, 2.06-2.56 \%$, and $0.79-0.90$, respectively, indicating that the current model and parameters have acceptable goodness of fit values and could simulate the soil water and heat flow of different depths in each treatment in 2019 well. The experimental data for 2018 were used to verify the model, and the results are shown in Figure 4. The ranges of RMSE, MRE and $R^{2}$ values for soil moisture and temperature were $0.015-0.018 \mathrm{~cm}^{3} \cdot \mathrm{cm}^{-3}, 5.41-6.68 \%$ and $0.58-0.69$, and $0.97-1.04{ }^{\circ} \mathrm{C}, 3.02-3.08 \%$ and $0.71-0.78$, respectively, indicating that the accuracy of the current model based on HYDRUS2D constructed for bare land furrow irrigation and full-film double-ridge hole irrigation is acceptable and that the applied modeling method is reasonable.

\subsection{Two-Dimensional Distribution of Soil Water and Heat}

We took the day before irrigation, the day of irrigation and the day after irrigation in 2019 (i.e., $29 \mathrm{~d}, 30 \mathrm{~d}$ and $31 \mathrm{~d}$ after sowing; the irrigation amounts were $60 \mathrm{~mm}, 40 \mathrm{~mm}$ and $40 \mathrm{~mm}$ in CK, RFWN and RFE, respectively) as an example to analyze the coupled water and heat flows through the two-dimensional simulations affected by different treatments. RFWN and RFE were covered with full film, and irrigation and rainfall both entered the soil through planting holes, while the infiltration methods of rainfall and irrigation were different under CK; thus, a group of data collected on the day before rainfall, the day of rainfall and the day after rainfall (i.e., $64 \mathrm{~d}, 65 \mathrm{~d}$ and $66 \mathrm{~d}$; rainfall was $23.5 \mathrm{~mm}$ ) were additionally selected under CK to analyze the distribution of soil moisture influenced by rainfall, while RFWN and RFE were not analyzed separately. The two-dimensional distributions of water and heat for each treatment are shown in Figure 5, and the water flow vector is shown in Figure 6. 


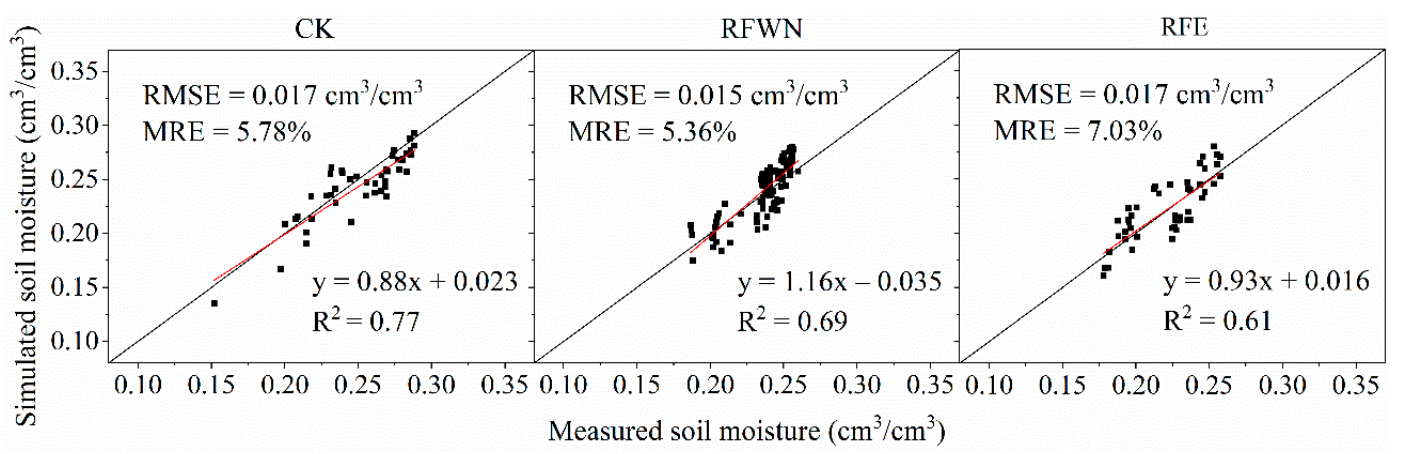

(a)

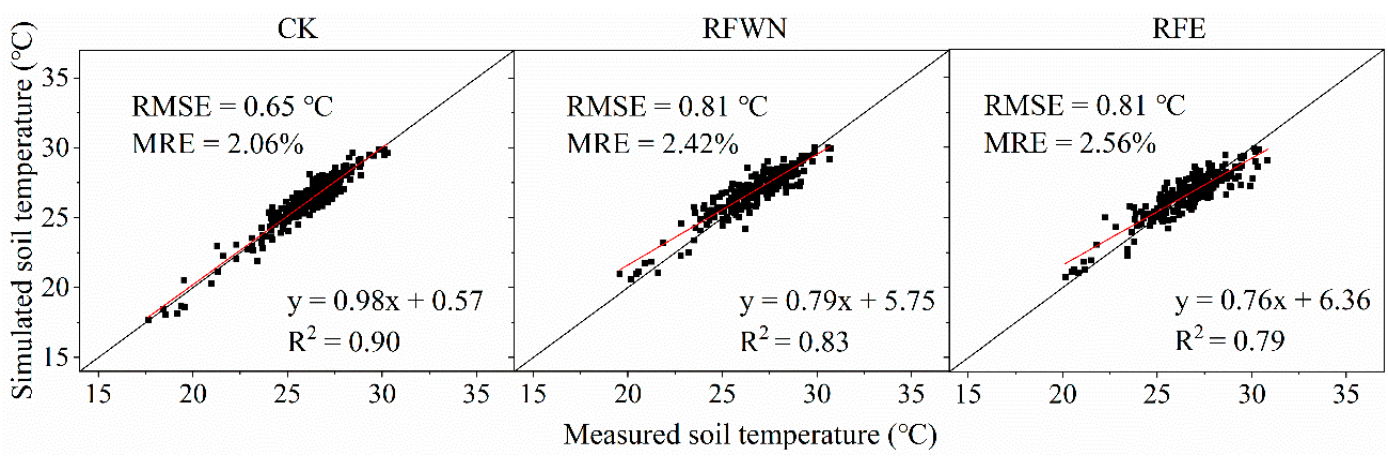

(b)

Figure 3. Calibration results of soil moisture and temperature based on HYDRUS-2D model in 2019. (a) Calibration results of soil moisture; (b) Calibration results of soil temperature.

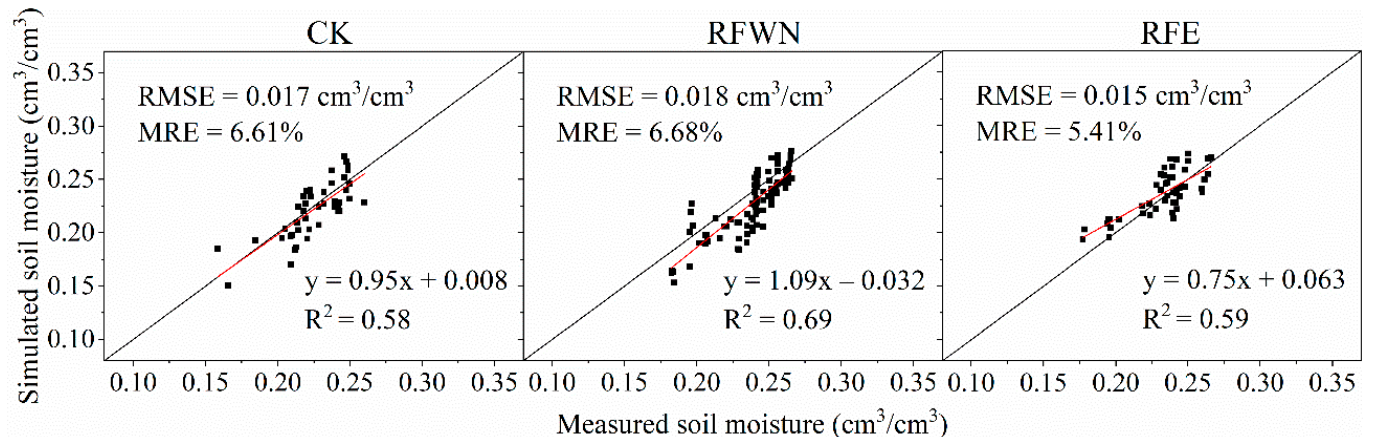

(a)

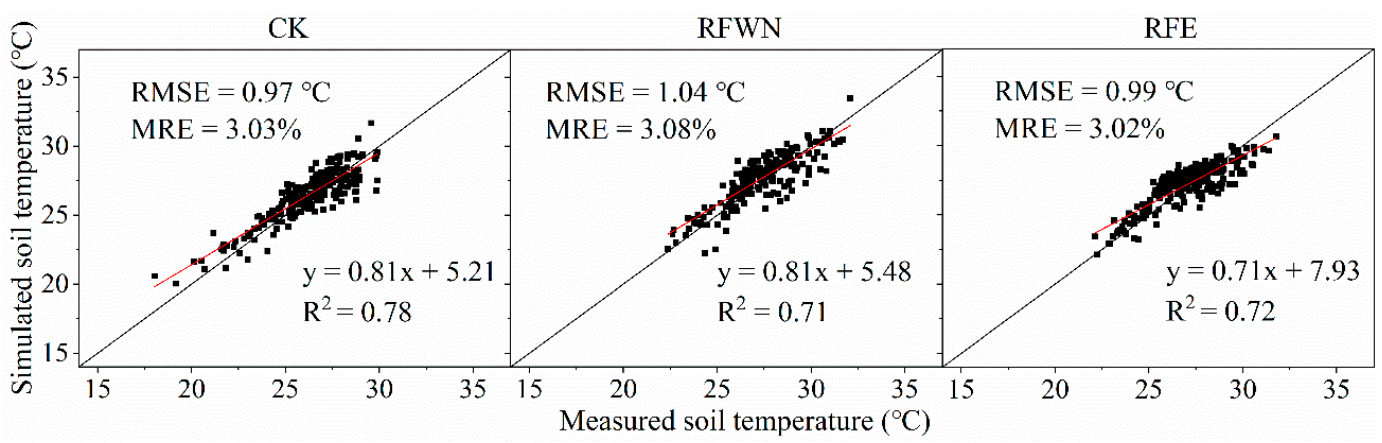

(b)

Figure 4. Validation results of soil moisture and temperature based on HYDRUS-2D model in 2018. (a) Validation results of soil moisture; (b) Validation results of soil temperature. 


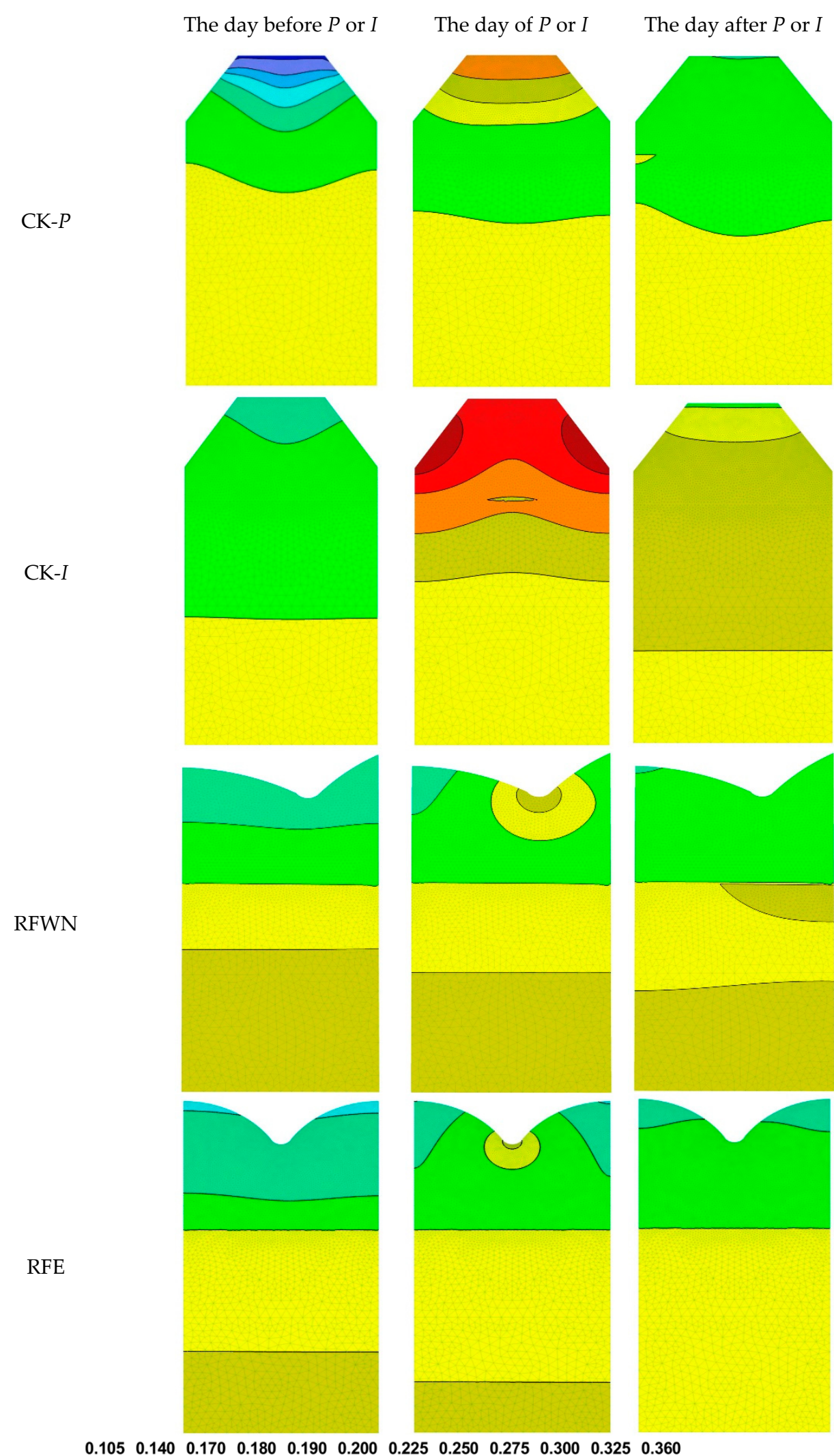

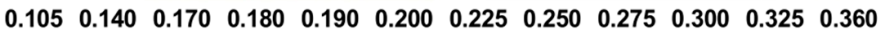

(a)

Figure 5. Cont. 


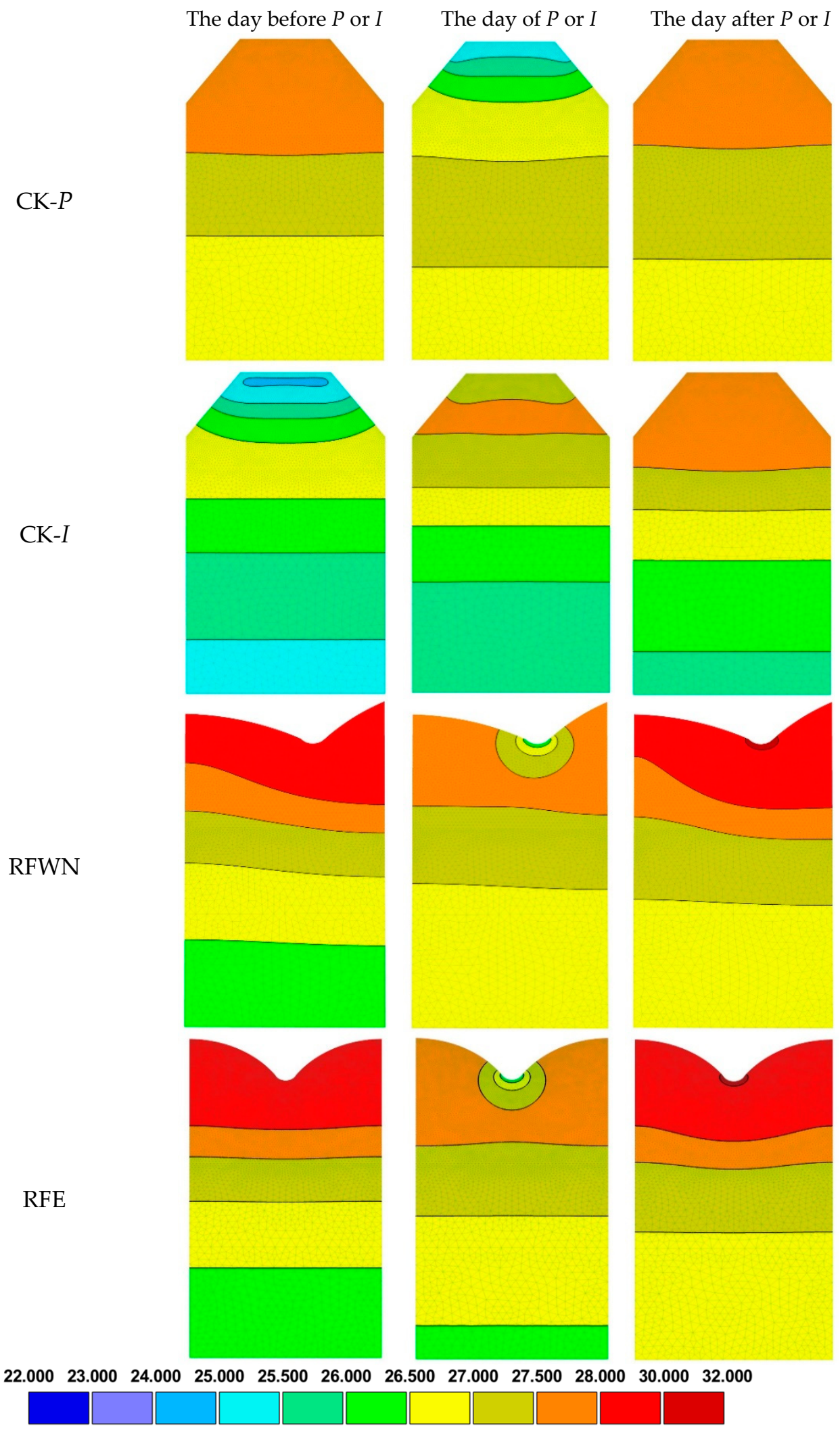

(b)

Figure 5. Two-dimensional distribution of soil water and heat. (a) Two-dimensional distribution of soil water during a rainfall or irrigation; (b) Two-dimensional distribution of soil temperature during a rainfall or irrigation; $P$ represents rainfall event and $I$ represents irrigation event. 


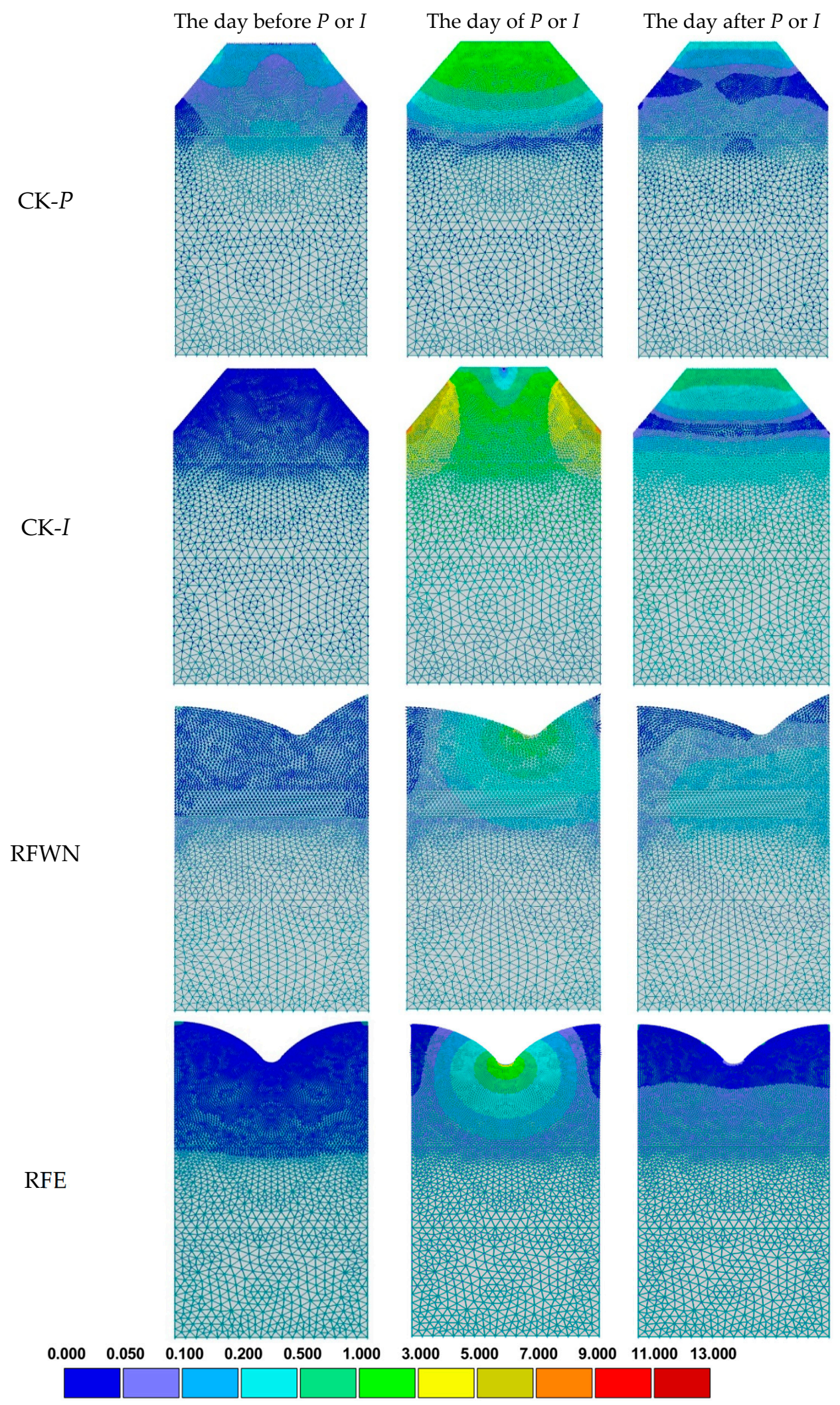

Figure 6. Simulated water flow vectors during a rainfall or irrigation; $P$ represents rainfall event and I represents irrigation event.

According to the analysis presented in Figures 5 and 6, both the plastic film mulching and irrigation methods had a great influence on water movement after rainfall or irrigation. 
The average soil moisture content within $1 \mathrm{~m}$ of each treatment increased gradually from top to bottom on the day before irrigation, and the order was RFWN $>$ RFE $>C K$, from large to small. The values for RFWN and RFE were $8.78 \%$ and $3.85 \%$ higher than CK, respectively, and the difference was mainly in the soil layer below $40 \mathrm{~cm}$. The water flow direction was upward at 0-60 cm depth but downward at 60-100 cm depth due to soil evaporation in CK, while the water flow direction in both RFWN and RFE was downward due to the obstruction of soil evaporation. On the day of irrigation, the water flow in CK infiltrated from the irrigation ditch and its direction in the $100 \mathrm{~cm}$ soil layer were downward, while the flow speed gradually decreased from the irrigation ditch to the crop side from top to bottom. The infiltration depth of furrow irrigation was deeper, up to $80-100 \mathrm{~cm}$, and the soil moisture content increased rapidly, which also indicated that deep seepage occurred more easily. Irrigation water was infiltrated from the planting hole in RFWN and RFE, and a wet ball was formed near the planting hole. The infiltration depth was less than $30 \mathrm{~cm}$, and the infiltration rate gradually decreased outward from the planting hole; irrigation was not sufficient to supplement the wide ridge tops of RFWN and the ridge tops of RFE. The increase in soil water content in the mulching group was smaller than that in bare land on the day of irrigation, which was mainly due to the blocking effect of mulching film on irrigation water. The soil moisture content of CK was still high, and a boundary layer was formed near $20 \mathrm{~cm}$ on the day after irrigation; the evaporation rate of soil was intensified after irrigation, especially the surface layer, and the water content within $100 \mathrm{~cm}$ increased first and then decreased with the depth. The water flow direction was downward in RFWN and RFE; RFWN moved from the top of narrow ridge to the top of wide ridge, while RFE moved from the planting hole to the two ridge tops, and the water content increased gradually from top to bottom. The soil moisture content of the day after irrigation was in the order of $\mathrm{CK}>\mathrm{RFWN}>\mathrm{RFE}$, from high to low. The analysis of a rainfall process treated by $\mathrm{CK}$ indicated that the rainfall infiltrated from the exposed surface, and the distribution of soil moisture content increased gradually from top to bottom and from crop side to both sides before rainfall. The water flowed downward in $0-30 \mathrm{~cm}$ and $70-100 \mathrm{~cm}$, but upward in 30-70 cm; meanwhile, the speed gradually decreased, causing the water content to decrease first and then increase from top to bottom. The surface water flow of $0-15 \mathrm{~cm}$ on the day after rainfall was upward and the velocity was large, which increased the evaporation on the soil surface. During the whole rainfall process, the soil moisture content below $50 \mathrm{~cm}$ was relatively stable, and it mainly affected the soil moisture content within $30 \mathrm{~cm}$. It can be seen from the comparison between rainfall and irrigation processes in CK that the difference was mainly associated with the infiltration location, influence depth, water distribution, etc., which was also affected by the infiltration volume, which mainly affected the wetting radius of the soil.

The average soil temperatures at $0-25 \mathrm{~cm}$ for RFWN and RFE were $6.91 \%\left(1.82{ }^{\circ} \mathrm{C}\right)$ and $3.97 \%\left(1.05^{\circ} \mathrm{C}\right)$ higher than that of $\mathrm{CK}$, and the amplification at $5 \mathrm{~cm}$ was the largest. The distribution of soil temperature in CK increased first and then decreased from top to bottom, while in RFWN and RFE, it was consistent and gradually decreased from top to bottom. This is mainly because the surface temperature of bare land is affected by solar radiation, sunshine duration and the temperature difference between day and night, while plastic film mulching weakens the turbulence exchange of upper air and eliminates latent heat exchange, which increased soil heat flux in our study and led to a higher soil temperature under plastic film than bare land. On the day of irrigation, the soil temperature showed a similar change zone of infiltration water flow, which began to decline from the top of the infiltration profile, and the range was essentially consistent with the influence range of irrigation infiltration, showing a coupled process of water and heat. The soil temperature rebounded on the day after irrigation, which was related to the weather, soil moisture content and mulching, and the temperature increased by $3.06{ }^{\circ} \mathrm{C}$ compared with the previous day. The soil temperatures of RFWN and RFE at $5 \mathrm{~cm}$ were both higher than that of $\mathrm{CK}$ by more than $3{ }^{\circ} \mathrm{C}$, related to film mulching; in addition, the soil heat capacity increased due to the higher soil moisture content of bare land, which led to a 
smaller temperature rise. The change in soil temperature caused by the rainfall process was similar to that caused by the irrigation process, and it also clearly showed the hydrothermal coupling process, with the difference being mainly in the coupling location.

\subsection{Dynamic Changes of Soil Water and Heat}

A group of profiles of $0-100 \mathrm{~cm}$ at a distance of $10 \mathrm{~cm}$ from a waxy corn plant in 2019 was taken as an example for analysis. Figure 7a shows the dynamic curve of soil moisture at different depths of this profile over time. As can be seen from the figure, the soil moisture content of each treatment increased with rainfall or irrigation, especially the surface layer, and then gradually decreased until the next rainfall or irrigation. Film mulching, irrigation methods and the irrigation amount all had a certain impact on soil moisture content. The results indicated that the fluctuation range of the soil moisture content of the full-film mulch was smaller than that of the bare soil. It had little effect on water content below $20 \mathrm{~cm}$ layers under RFWN and RFE due to its ability to hinder the rainfall, irrigation and soil evaporation of plastic mulching. However, the open surface of bare soil could allow more water infiltration when rainfall or irrigation events occurred, so that the soil moisture content below $40 \mathrm{~cm}$ was almost unaffected by rainfall, while irrigation had a certain influence on soil moisture content within $1 \mathrm{~m}$, and the increase in water content decreased from top to bottom, which was related to whether the soil surface was covered and the irrigation method. Comparing the changes in soil moisture content during irrigation under CK, RFWN and RFE (30 d, $45 \mathrm{~d}$ and $60 \mathrm{~d}$ after sowing), furrow irrigation was used for CK and film hole irrigation for RFWN and RFE. It could be seen that furrow irrigation had a deeper infiltration depth, but the slope of the decline in water content was greater. However, film hole irrigation was insufficient to supplement the soil moisture content below 20-40 cm; the plastic film obstructed soil evaporation so that the water content decreased slowly and changed little over time. With the increase in the irrigation amount, the peak value after irrigation also increased. The simulation accuracy of the soil layer below $40 \mathrm{~cm}$ was higher than 0-40 cm, especially 0-20 cm, of which the simulated value was lower than observed. This is related to the boundary selection and parameters indicated by the model; in addition, the possible damage, dislocation and tearing of the mulching film with the passage of time after mulching, which might increase water infiltration, were not considered in the model, which might have contributed to the above results.

Figure $7 \mathrm{~b}$ shows the dynamic change curve of ground temperature with time at $5 \mathrm{~cm}, 15 \mathrm{~cm}$ and $25 \mathrm{~cm}$ under different treatments. The results showed that the variation trends of soil temperature at different depths were similar in each treatment, and the fluctuation at $5 \mathrm{~cm}$ was larger than those at $15 \mathrm{~cm}$ and $25 \mathrm{~cm}$. The average measured values during the growth period of film mulching at $5 \mathrm{~cm}$ and $15 \mathrm{~cm}$ increased by approximately $5.5 \%$ and $2.2 \%$, respectively, compared to that of bare soil, while the effect at $25 \mathrm{~cm}$ was not significant. The amplitude of soil temperature in bare land was larger than that in plastic film mulching, and the amplitude differences were $2.4-2.64{ }^{\circ} \mathrm{C}, 1.83-2.69{ }^{\circ} \mathrm{C}$ and $0.92-1.0^{\circ} \mathrm{C}$ at $5 \mathrm{~cm}, 15 \mathrm{~cm}$ and $25 \mathrm{~cm}$, respectively, which indicated that plastic film mulching could suppress temperature fluctuations by increasing the minimum temperature or decreasing the maximum temperature, which was consistent with the observed results of Petrone et al. [44]. The warming effect of mulching began to weaken at the middle and late periods until the difference was not obvious, which was caused by the increase in the canopy as the growth period progressed. 


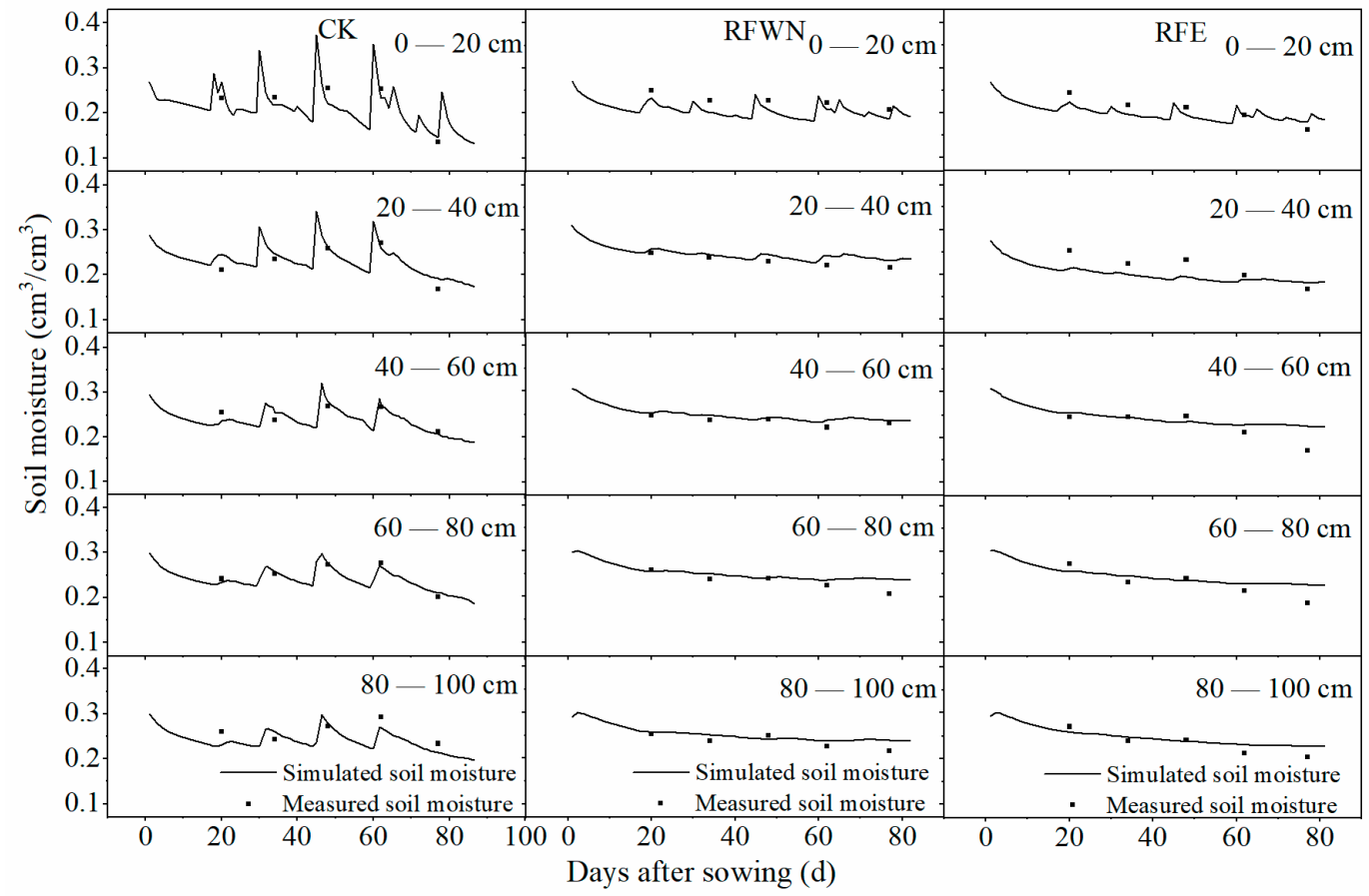

(a)

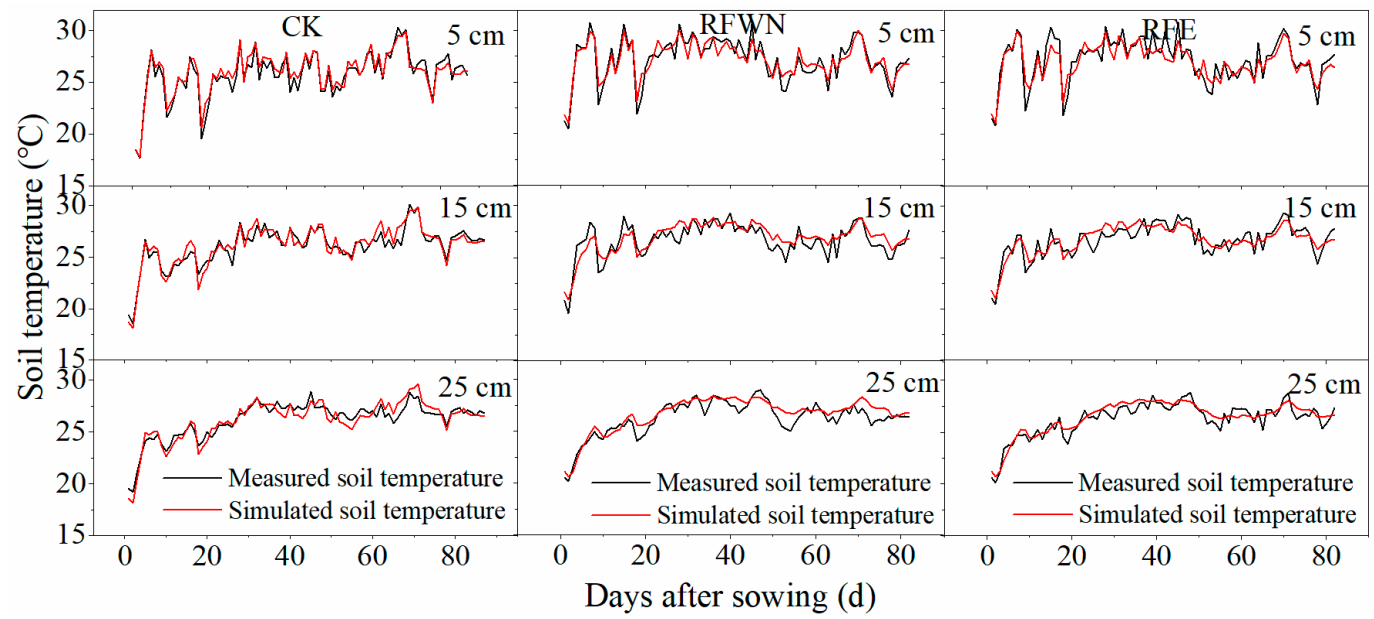

(b)

Figure 7. Dynamic changes in soil water and heat. (a) Soil water dynamic change; (b) Soil temperature change.

\subsection{Soil Water Balance}

Table 4 shows the water balance analysis results for the simulated flow area, including cumulative infiltration, evaporation, root water uptake, deep drainage and changes in soil water storage. Compared with bare soil, the amounts of irrigation for plastic mulching were 50\% (2018) and 83.33\% (2019) of bare soil, while the amount of soil infiltration increased by $20.04-24.4 \%$, which was mainly due to the double-ridge full-film mulching planting, which could concentrate the rainfall on the ridge surface into the planting furrow, thereby increasing the rainfall infiltration. Plastic film mulching also greatly reduced soil evaporation (84.71-93.73\%) and field evapotranspiration (12.02-21.75\%), while it increased crop root water uptake (25.87-40.98\%) and T/ET (48.85-80.15\%); in other words, plastic film mulching could reduce the ineffective consumption of soil water and increase the efficiency of water use in the field. The negative value of the change in soil water storage indicated the loss of soil moisture at the end of the growth period for the simulated area, indicating that the mulching film is beneficial for the storage of soil moisture. Although 
plastic film mulch would greatly reduce soil evaporation, it also increased deep drainage to a certain extent, as the upward movement of water was hindered under plastic film mulch (Figure 7) and there was increased drainage due to free drainage at the lower boundary. Our conclusions on infiltration and drainage are inconsistent with the conclusions made under similar conditions in [26]. This is mainly due to the different simulation area settings (the simulation depth in this article was $0-100 \mathrm{~cm}$, while that presented in the literature was $250 \mathrm{~cm}$ ) and the two-times higher rainfall as the model input item in this article due to the ridge and furrow structure.

Table 4. Estimated water balance with HYDRUS-2D under different treatments for growth period.

\begin{tabular}{|c|c|c|c|c|c|c|c|c|}
\hline Year & Treatments & $\begin{array}{l}\text { Infiltration } \\
\quad(\mathrm{mm})\end{array}$ & $\begin{array}{l}\text { Evaporation } \\
(\mathrm{mm})\end{array}$ & $\begin{array}{l}R W U \\
(\mathrm{~mm})\end{array}$ & $\begin{array}{c}\text { Drainage } \\
(\mathrm{mm})\end{array}$ & $\begin{array}{c}\Delta W \\
(\mathrm{~mm})\end{array}$ & $\begin{array}{c}E T \\
(\mathrm{~mm})\end{array}$ & $\begin{array}{c}T / E T \\
(\%)\end{array}$ \\
\hline \multirow{3}{*}{2018} & $\mathrm{CK}$ & 301.60 & 119.71 & 137.39 & 72.25 & -27.75 & 257.10 & $53.44 \%$ \\
\hline & RFWN & 375.20 & 7.50 & 193.69 & 121.09 & 52.92 & 201.19 & $96.27 \%$ \\
\hline & RFE & 371.60 & 11.51 & 191.54 & 110.98 & 57.57 & 203.05 & $94.33 \%$ \\
\hline \multirow{3}{*}{2019} & CK & 341.90 & 108.20 & 182.94 & 99.29 & -48.53 & 291.14 & $62.84 \%$ \\
\hline & RFWN & 410.40 & 7.50 & 230.27 & 118.24 & 54.39 & 237.77 & $96.85 \%$ \\
\hline & RFE & 410.40 & 16.54 & 239.61 & 110.23 & 44.02 & 256.15 & $93.54 \%$ \\
\hline
\end{tabular}

According to the Water Resources Bulletin of Shanxi Province from 2018 to 2019, 2018 was a normal year and 2019 was a dry year, with response frequencies of $42.1 \%$ and $65.3 \%$, respectively. Different year types had little impact on soil evaporation, and it had greater impact on bare land planting, as the T/ET of the same irrigation system was higher in the dry year. RFWN and RFE were more stable in $E$, Drainage, $\Delta W$ and $T / E T$, whose $T / E T$ values were much higher than that of CK, and RFWN significantly increased T/ET compared with RFE. More irrigation water led to more RWU and ET.

\section{Discussion}

\subsection{Effect of Plastic Film Mulching on Soil Moisture and Heat}

It is clear that the full mulching of the ridge and furrow structure has a significant impact on the micro-ecological environment on the soil surface. Wang et al. [45] studied the soil moisture and heat of Lycium barbarum under different planting conditions on the Qinghai-Tibet Plateau and found that film mulching significantly increased the soil water requirement of 10-110 $\mathrm{cm}$ and the surface soil heat absorption capacity (soil temperature at $20 \mathrm{~cm}$ ) compared with traditional plain cropping. Plastic film mulching with ridge and furrow provided better soil hydrothermal conditions and was more conducive to deep water storage than plain cropping film mulching; similar trends were observed in the planting of corn [46], potato [47] and wheat [31], which are essentially consistent with the conclusions of this study. In this study, full-film mulching significantly increased the soil temperature at $5 \mathrm{~cm}-15 \mathrm{~cm}$ and suppressed soil temperature fluctuations by increasing the minimum temperature or decreasing the maximum temperature, which was consistent with the aforementioned study [44]. However, Zhao et al. [31] showed that plastic mulching caused a strong warming effect, resulting in a higher amplitude of topsoil temperature with slightly different fluctuation patterns. However, the warming effect of plastic mulching will weaken with the progression of the growth period [48], mainly because the increasing canopy gradually blocks light and weakens the warming effect [49], which is consistent with the results of this study. It can be concluded that the fluctuation of the upper soil was largely due to weather, regardless of mulching, while the film mulching could reduce the fluctuation of soil moisture and heat, which is very important for crop growth. The alternation of soil drying and wetting will lead to an increase in soil moisture fluctuation, thus posing a certain risk to crop yields [50]. Therefore, in this study, plastic film mulching, especially RFWN, showed the lowest fluctuation of water and heat, which was more conducive to crop growth. 
Research on the effect of plastic film mulching on soil evapotranspiration has not yet reached a consensus. In this study, plastic film mulching was shown to significantly reduce soil evaporation and field evapotranspiration and increase crop transpiration, which is consistent with the literature [51-53], while some studies have shown that although mulching can reduce soil evaporation, it can increase crop transpiration and thus increase field evapotranspiration $[45,54,55]$. This is because the effect of plastic mulching on crop transpiration is different due to meteorological conditions, varieties, the proportion of plastic mulching, irrigation and other factors; consequently, the impact of plastic mulching on the total amount of evapotranspiration is not yet agreed upon.

\subsection{The Influence of Ridge Patterns on Soil Moisture and Heat}

The RFMS can collect the water on ridges covered by impervious plastic film into the furrows and infiltrate through planting holes on the film [6]. Studies have shown that this system can reduce soil water evaporation, improve soil temperature and effectively increase crop absorption and the utilization of light rainfall and soil water and heat resources [56]. Jiang and Li [57] used the dye tracer method to simulate the soil distribution after $24 \mathrm{~h}$ of rainfall under $2 \mathrm{~min}, 4 \mathrm{~min}$ and $6 \mathrm{~min}$ under RFWN conditions, and the results showed that rainfall infiltrated through the entire soil surface under the condition of conventional planting in bare land, while RFWN occurred through a narrow furrow, which is consistent with the results of this study. RFWN significantly increased the soil water content in the dyeing area within the range of $0-20 \mathrm{~cm} 24 \mathrm{~h}$ after rainfall, and the depth of infiltration perpendicular to the planting line was greater, which is different from the results of this study. This is because the literature ignores the canopy interception of the simulation area and the distribution of soil moisture is influenced by root water uptake; in addition, in the experiment, the ridges were usually not flat, and the indentation of the ridge top hindered soil infiltration to a certain extent. Eldoma et al. [49] studied the effects of RFWN and RFE on maize planting under rain-fed conditions in semi-arid areas, and the results showed that the ridge pattern did not affect the soil temperature and had no consistent effect on soil moisture, and the two patterns showed no significant differences in crop growth and yield composition. The effect of film mulching is much greater than that of the ridge type on the growth and development of maize. In this study, RFWN and RFE had little effect on soil temperature and no consistent effect was found, which is in line with the conclusions presented in the literature. In terms of soil moisture content, RFWN was slightly higher than RFE throughout the entire growth period. Ten nodes in RFWN, which were the same as RFE, were selected to analyze the average water content during the growth period. It could be concluded that the soil water content in RFWN increased by $0.7 \%$ to $3.5 \%$ compared with RFE in other nodes, except for two nodes with $20-40 \mathrm{~cm}$ height, and the increment in 2019 was higher than that in 2018. However, the moisture content of RFWN at 20-40 cm could increase by more than 20\% compared with RFE in 2019, and the increase mechanism may relate to the rainfall year type and root water uptake and is yet to be further studied. The comparison of each node under the RFWN condition during the two-year experiment showed that the farther the transverse from the planting row in the simulated area, the higher the water content, and the water content of the narrow ridge was slightly higher than that of the wide ridge, but the difference was small, at no more than $1 \%$.

\section{Conclusions}

The HYDRUS-2D model was calibrated and verified in this paper, and the RMSE and MRE ranges of soil moisture and temperature under different treatments were $0.015-0.018 \mathrm{~cm}^{3} \cdot \mathrm{cm}^{-3}$, $5.36-7.03 \%$ and $0.65-1.04{ }^{\circ} \mathrm{C}, 2.06-3.08 \%$, respectively, which showed good fitness and can be used to simulate the soil water and heat flow under the conditions of full-film double-ridge film-hole irrigation and bare land furrow irrigation. The simulation results showed that the order of soil moisture was RFWN $>$ RFE $>$ CK when there was no water supplement, and the distribution of that under different treatments increased gradually 
from top to bottom and from crop side to both sides; it was slightly higher in narrow ridges than in wide ridges under RFWN, while the film mulching fluctuated less than bare soil. The infiltration film hole formed a wet ball near $20 \mathrm{~cm}$ depth during irrigation, while, during furrow irrigation, the infiltration formed a wet front inward and downward from the ditch wall. The infiltration of bare land during rainfall occurred from the surface soil and advanced in layers inside the soil, while the infiltration law of plastic film mulching was consistent with that of irrigation, and the evaporation of bare soil increased greatly after rainfall or irrigation. Film mulching suppressed the fluctuation amplitude of soil temperature, which was significantly higher than that of bare land, and the warming effect weakened with the increase in depth and the progression of the growth period. In the process of rainfall or irrigation, soil temperature displayed a similar change zone with the infiltration of water, showing an obvious water-heat coupling process.

RFMS could increase infiltration (it can collect rainwater on the ridge surface to the planting furrow), root water uptake and the E/ET ratio, reduce soil evaporation and field evapotranspiration, improve soil water storage and increase water use efficiency. Compared with RFE, RFWN could increase soil moisture content and E/ET to a certain extent and lessen water and heat fluctuations, which is more conducive to crop growth.

Author Contributions: R.L. edited the original draft; J.M., X.S., X.G. and L.Z. reviewed and edited the draft; J.M. provided the funding. All authors have read and agreed to the published version of the manuscript.

Funding: This research was financially supported by the Key Research and Development Program (Agriculture) Project (201703D211009) of Shanxi Province.

Acknowledgments: The authors thank the School of Water Resources Science and Engineering for providing the site for experiment and collecting data.

Conflicts of Interest: The authors declare no conflict of interest.

\section{References}

1. Zribi, W.; Aragüés, R.; Medina, E.; Faci, J.M. Efficiency of inorganic and organic mulching materials for soil evaporation control. Soil Tillage Res. 2015, 148, 40-45. [CrossRef]

2. Kader, B.M.; Senge, M.; Mojid, M.A.; Ito, K. Recent advances in mulching materials and methods for modifying soil environment. Soil Tillage Res. 2017, 168, 155-166. [CrossRef]

3. Shen, Q.; Ding, R.; Du, T.; Tong, L.; Li, S. Water use effectiveness is enhanced using film mulch through increasing transpiration and decreasing evapotranspiration. Water 2019, 11, 1153. [CrossRef]

4. Zhang, D.; Liao, Y.; Jia, Z. Research advances and prospects of film mulching in arid and semi-arid areas. Agric. Res. Arid Areas 2005, 23, 208-213.

5. Liu, Q.; Chen, Y.; Liu, Y.; Wen, X.; Liao, Y. Coupling effects of plastic film mulching and urea types on water use efficiency and grain yield of maize in the Loess Plateau, China. Soil Tillage Res. 2016, 157, 1-10. [CrossRef]

6. Gan, Y.; Siddique, K.; Turner, N.C.; Li, X.; Liu, L. Ridge-furrow mulching systems-an innovative technique for boosting crop productivity in semiarid rain-fed environments. Adv. Agron. 2013, 118, 429-476.

7. Gu, X.; Cai, H.; Chen, P.; Li, Y.; Fang, H.; Li, Y. Ridge-furrow film mulching improves water and nitrogen use efficiencies under reduced irrigation and nitrogen applications in wheat field. Field Crop. Res. 2021, 270, 108214. [CrossRef]

8. Gu, X.; Li, Y.; Du, Y.; Yin, M. Ridge-furrow rainwater harvesting with supplemental irrigation to improve seed yield and water use efficiency of winter oilseed rape (Brassica napus L.). J. Integr. Agr. 2017, 16, 1162-1172. [CrossRef]

9. Ren, X.; Chen, X.; Cai, T.; Wei, T.; Yang, W.; Shahzad, A.; Peng, Z.; Jia, Z. Effects of Ridge-Furrow System Combined with Different Degradable Mulching Materials on Soil Water Conservation and Crop Production in Semi-Humid Areas of China. Front. Plant Sci. 2017, 8, 1877-1886. [CrossRef] [PubMed]

10. Liu, P.; Wang, H.; Li, L.; Liu, X.; Qian, R.; Wang, J.; Yan, X.; Cai, T.; Zhang, P.; Jia, Z.; et al. Ridge-furrow mulching system regulates hydrothermal conditions to promote maize yield and efficient water use in rainfed farming area. Agric. Water Manag. 2020, 232, 106041. [CrossRef]

11. Li, W.; Xiong, L.; Wang, C.; Liao, Y.; Wu, W. Optimized ridge-furrow with plastic film mulching system to use precipitation efficiently for winter wheat production in dry semi-humid areas. Agric. Water Manag. 2019, 218, 211-221. [CrossRef]

12. Qin, S.; Yeboah, S.; Wang, D.; Zhang, J.; Unc, A. Effects of ridge-furrow and plastic mulching planting patterns on microflora and potato tuber yield in continuous cropping soil. Soil Use Manag. 2016, 32, 465-473. [CrossRef]

13. Gu, X.; Cai, H.; Du, Y.; Li, Y. Effects of film mulching and nitrogen fertilization on rhizosphere soil environment, root growth and nutrient uptake of winter oilseed rape in northwest China. Soil Tillage Res. 2019, 187, 194-203. [CrossRef] 
14. Yang, J.; Mao, X.; Wang, K.; Yang, W. The coupled impact of plastic film mulching and deficit irrigation on soil water/heat transfer and water use efficiency of spring wheat in Northwest China. Agric. Water Manag. 2018, 201, 232-245. [CrossRef]

15. Zhao, Y.; Mao, X.; Shukla, M.K.; Li, S. Modeling Soil Water-Heat Dynamic Changes in Seed-Maize Fields under Film Mulching and Deficit Irrigation Conditions. Water 2020, 12, 1330. [CrossRef]

16. Chen, B.; Liu, E.; Mei, X.; Yan, C.; Garré, S. Modelling soil water dynamic in rain-fed spring maize field with plastic mulching Agric. Water Manag. 2018, 198, 19-27. [CrossRef]

17. Elias, E.A.; Rogerio, C.; Torriani, H.H.; Quirijn, D. Analytical soil-temperature model: Correction for temporal variation of daily amplitude. Soil Sci. Soc. Am. J. 2004, 68, 784-788. [CrossRef]

18. Ma, B.; Wang, C.; Li, F.; Qiang, S.; Zhao, H. Ridge-furrow with full plastic film mulching improves water use efficiency and tuber yields of potato in a semiarid rainfed ecosystem. Field Crop. Res. 2014, 161, 137-148.

19. Wang, Q.; Ren, X.; Song, X.; Hu, G.; Zhang, E.; Wang, H.; Maureen, V. The optimum ridge-furrow ratio and suitable ridge-covering material in rainwater harvesting for oats production in semiarid regions of China. Field Crop. Res. 2015, 172, 106-118.

20. Wang, X.; Chen, M.; Yi, X.; Fu, G. Effects of ridge width and planting density on corn yields in rainwater-harvesting system with plastic film mulching on ridge. Trans. Chin. Soc. Agric. Eng. 2009, 25, 40-47.

21. Zhou, L.; Li, F.; Jin, S.; Song, Y. How two ridges and the furrow mulched with plastic film affect soil water, soil temperature and yield of maize on the semiarid Loess Plateau of China. Field Crop. Res. 2009, 113, 41-47. [CrossRef]

22. Li, F.; Wang, J.; Xu, J.; Xu, H. Productivity and soil response to plastic film mulching durations for spring wheat on entisols in the semiarid Loess Plateau of China. Soil Tillage Res. 2004, 78, 9-20. [CrossRef]

23. Li, F.; Guo, A.; Hong, W. Effects of plastic film mulch on yield of spring wheat. Field Crops Res. 1999, 63, 79-86. [CrossRef]

24. Xia, Z.; Zhang, G.; Zhang, S.; Wang, Q.; Fu, Y.; Lu, H. Efficacy of Root Zone Temperature Increase in Root and Shoot Development and Hormone Changes in Different Maize Genotypes. Agriculture 2021, 11, 477. [CrossRef]

25. Li, J.; Zou, Z. Effects of air temperature, solar radiation and soil water on dry matter accumulation and allocation of greenhouse muskmelon seedlings and related simulation models. Chin. J. Appl. Ecol. 2007, 18, 2715-2721, (In Chinese with English abstract).

26. Liu, X.; Wang, Y.; Yan, X.; Hou, H.; Liu, P.; Cai, T.; Zhang, P.; Jia, Z.; Ren, X.; Chen, X. Appropriate ridge-furrow ratio can enhance crop production and resource use efficiency by improving soil moisture and thermal condition in a semi-arid region. Agric. Water Manag. 2020, 240, 106289. [CrossRef]

27. Šimuůnek, J.; van Genuchten, M.T.; Šejna, M. Recent Developments and Applications of the HYDRUS Computer Software Packages. Vadose Zone J. 2016, 15, 1-25. [CrossRef]

28. Bufon, V.B.; Lascano, R.J.; Bednarz, C.; Booker, J.D.; Gitz, D.C. Soil water content on drip irrigated cotton: Comparison of measured and simulated values obtained with the Hydrus 2-D model. Irrig. Sci. 2011, 30, 259-273. [CrossRef]

29. Kanda, E.K.; Senzanje, A.; Mabhaudhi, T. Modelling soil water distribution under Moistube irrigation for cowpea (VIGNA unguiculata (L.) Walp.) crop. Irrig. Drain. 2020, 69, 1116-1132. [CrossRef]

30. Zhang, Y.; Feng, S.; Wang, F.; Binley, A. Simulation of soil water flow and heat transport in drip irrigated potato field with raised beds and full plastic-film mulch in a semiarid area. Agric. Water Manag. 2018, 209, 178-187. [CrossRef]

31. Zhao, Y.; Zhai, X.; Wang, Z.; Li, H.; Jiang, R.; Hill, R.L.; Si, B.; Hao, F. Simulation of soil water and heat flow in ridge cultivation with plastic film mulching system on the Chinese Loess Plateau. Agric. Water Manag. 2018, 202, 99-112. [CrossRef]

32. Kader, M.A.; Nakamura, K.; Senge, M.; Mojid, M.A. Two-dimensional numerical simulations of soil-water and heat flow in a rainfed soybean field under plastic mulching. Water Supply. 2021, 21, 2615-2632. [CrossRef]

33. Richards, L.A. Capillary conduction of liquids through porous mediuns. Physics 1931, 1, 318-333. [CrossRef]

34. Van Genuchten, M.T. A closed-form equation for predicting the hydraulic conductivity of unsaturated soils. Soil Sci. Soc. Am. J. 1980, 44, 892-898. [CrossRef]

35. Mualem, Y. A New Model for Predicting the Hydraulic Conductivity of Unsaturated Porous Media. Water Resour. Res. 1976, 12, 513-522. [CrossRef]

36. Feddes, R.A.; Kowalik, P.J.; Zaradny, H. Simulation of Field Water Use and Crop Yield; John Wiley and Sons: New York, NY, USA, 1978.

37. Wesseling, J.G.; Brandyk, T. Introduction of the Occurrence of High Groundwater Levels and Surface Water Storage in Computer Program SWATRE; Instituut voor Cultuurtechniek en Waterhuishouding: Wageningen, The Netherlands, 1985.

38. Vrugt, J.A.; Hopmans, J.W.; Šimunek, J. Calibration of a Two-Dimensional Root Water Uptake Model. Soil Sci. Soc. Am. J. 2001, 65, 1027-1037. [CrossRef]

39. Sophocleous, M. Analysis of water and heat flow in unsaturated-saturated porous media. Water Resour. Res. 1979, 15, 1195-1206. [CrossRef]

40. Šimůnek, J.; van Genuchten, M.T.; Šejna, M. Development and Applications of the HYDRUS and STANMOD Software Packages and Related Codes. Vadose Zone J. 2008, 7, 587-600. [CrossRef]

41. Šimůnek, J.; Suarez, D.L. UNSATCHEM-2D Code for Simulating Two-Dimensional Variably Saturated Water Flow, Heat Transport, Carbon Dioxide Production and Transport, and Multicomponent Solute Transport with Major Ion Equilibrium and Kinetic Chemistry; Version 1.1, Research Report No. 128.; U.S. Salinity Laboratory, USDA, ARS: Riverside, CA, USA, 1993.

42. Chung, S.; Horton, R. Soil heat and water flow with a partial surface mulch. Water Resour. Res. 1987, 23, 2175-2186. [CrossRef]

43. Allen, R.G.; Pereira, L.S.; Raes, D.; Smith, M. Crop evapotranspiration-Guidelines for computing crop water requirements. FAO Irrig. Drain. Pap. 56. 1998, 300, D05109. 
44. Petrone, R.M.; Waddington, J.M.; Price, J.S. Ecosystem scale evapotranspiration and net CO2 exchange from a restored peatland. Hydrol. Proc. 2001, 15, 2839-2845. [CrossRef]

45. Wang, J.; Gao, X.; Zhou, Y.; Wu, P.; Zhao, X. Impact of conservation practices on soil hydrothermal properties and crop water use efficiency in a dry agricultural region of the tibetan plateau. Soil Tillage Res. 2020, 200, 104619. [CrossRef]

46. Qi, Z.; Feng, H.; Zhao, Y.; Zhang, T.; Yang, A.; Zhang, Z. Spatial distribution and simulation of soil moisture and salinity under mulched drip irrigation combined with tillage in an arid saline irrigation district, northwest China. Agric. Water Manag. 2018, 201, 219-231. [CrossRef]

47. Ruidisch, M.; Kettering, J.; Arnhold, S.; Huwe, B. Modeling water flow in a plastic mulched ridge cultivation system on hillslopes affected by South Korean summer monsoon. Agric. Water Manag. 2013, 116, 204-217. [CrossRef]

48. Hou, X.; Wang, F.; Han, J.; Kang, S.; Feng, S. Duration of plastic mulch for potato growth under drip irrigation in an arid region of Northwest China. Agric. For. Meteorol. 2010, 150, 115-121. [CrossRef]

49. Eldoma, I.M.; Li, M.; Zhang, F.; Li, F. Alternate or equal ridge-furrow pattern: Which is better for maize production in the rain-fed semi-arid Loess Plateau of China? Field Crop. Res. 2016, 191, 131-138. [CrossRef]

50. Parihar, C.M.; Nayak, H.S.; Rai, V.K.; Jat, S.L.; Parihar, N.; Aggarwal, P.; Mishra, A.K. Soil water dynamics, water productivity and radiation use efficiency of maize under multi-year conservation agriculture during contrasting rainfall events. Field Crop. Res. 2019, 241, 107570. [CrossRef]

51. Chen, Z.; Sun, S.; Zhu, Z.; Jiang, H.; Zhang, X. Assessing the effects of plant density and plastic film mulch on maize evaporation and transpiration using dual crop coefficient approach. Agric. Water Manag. 2019, 225, 105765. [CrossRef]

52. Doss, B.D.; King, C.; Patterson, R.M. Yield Components and Water Use by Silage Corn with Irrigation, Plastic Mulch, Nitrogen Fertilization, and Plant Spacing. Agron. J. 1970, 62, 541-543. [CrossRef]

53. Li, S.; Wang, Z.; Li, S.; Gao, Y.; Tian, X. Effect of plastic sheet mulch, wheat straw mulch, and maize growth on water loss by evaporation in dryland areas of China-ScienceDirect. Agric. Water Manag. 2013, 116, 39-49. [CrossRef]

54. Bu, L.; Liu, J.; Zhu, L.; Luo, S.; Chen, X.; Li, S.; Hill, R.L.; Zhao, Y. The effects of mulching on maize growth, yield and water use in a semi-arid region. Agric. Water Manag. 2013, 123, 71-78. [CrossRef]

55. Mo, F.; Wang, J.; Zhou, H.; Luo, C.; Zhang, X.; Li, X.; Li, F.; Xiong, L.; Kavagi, L.; Nguluu, S. Ridge-furrow plastic-mulching with balanced fertilization in rainfed maize (Zea mays L.): An adaptive management in east African Plateau. Agric. For. Meteorol. 2017, 236, 100-112. [CrossRef]

56. Duan, C.; Chen, G.; Hu, Y.; Wu, S.; Feng, H.; Dong, Q. Alternating wide ridges and narrow furrows with film mulching improves soil hydrothermal conditions and maize water use efficiency in dry sub-humid regions. Agric. Water Manag. 2021, 245, 106559. [CrossRef]

57. Jiang, X.; Li, X. Assessing the effects of plastic film fully mulched ridge-furrow on rainwater distribution in soil using dye tracer and simulated rainfall. Soil Tillage Res. 2015, 152, 67-73. [CrossRef] 